\title{
Materials processing under microgravity conditions using drop tobes
}

\author{
K CHATTOPADHYAY* and M K TIWARI ${ }^{\dagger}$ \\ Department of Metallurgy, Indian Institute of Science, Bangalore 560012 India \\ ${ }^{\dagger}$ ISRO Headquarters, Antariksha Bhavan, New BEL Road, Bangalote 560094, India \\ MS received 8 April 1991; revised 5 June 1991
}

Abstract. Drop tube provides a low-cost alternative to study the influence of microgravity in materials processing. In the present paper, the current status of the drop tubes and associated experiments on materials processing are reviewed. Emphasis is placed on the advantages and limitations of these studies. It is pointed out that despite size limitation, large opportunities exist to study the fundamental aspects of the influence of gravity in materials processing.

Keywords. Materials processing; microgravity; drop tubes; drop towers; solidification.

\section{Introduction}

Materials processing in general involves complex heat and mass transfer as well as phase transformations. These are often affected by gravity either directly or indirectly. With the advent of interest in microgravity, increasing efforts are directed towards the understanding of the role of gravity in different processing techniques. Among these, attention has so far been primarily focused on solidification processing. Although the effect of gravity in this case is more transparent and amenable to carefui study, part of the interest also stems from a perceived economic advantage of space processing of certain difficult materials. Fabrication of microspherical capsules is one such example (Lee 1983). Therefore, in the present study major emphasis is placed on solidification processing without any prejudice and judgement to the potential of microgravity in controlling other processing routes.

One of the most important parameters for microgravity processing is the processing time available under microgravity conditions. This is, in principle, infinite on board a space station, which is perpetually in a free-fall situation. On a spacecraft, it is limited by the return schedule of the craft. However, the actual time depends on economic considerations. Next in line are sounding rocket experiments, utilizing the free-fall time of the payload. The concept of achieving microgravity during free-fall is also utilized in earth-based experiments involving high aititude aircraft programmed to have free-fall trajectories during the flight. The drop tube and drop towers utilize the same principle of free-fall to obtain microgravity conditions. The duration time is only of the order of a couple of seconds in these earth-based experiments and is an order of magnitude less than the space-based techniques (figure 1). However the advantage includes very low-time interval for repetition of the experiments as well as the ability to monitor and change the parameters with ease and economy. Needless to say the short microgravity time available represents the major disadvantage and calls for a careful design of experiments.

\footnotetext{
* For correspondence
} 


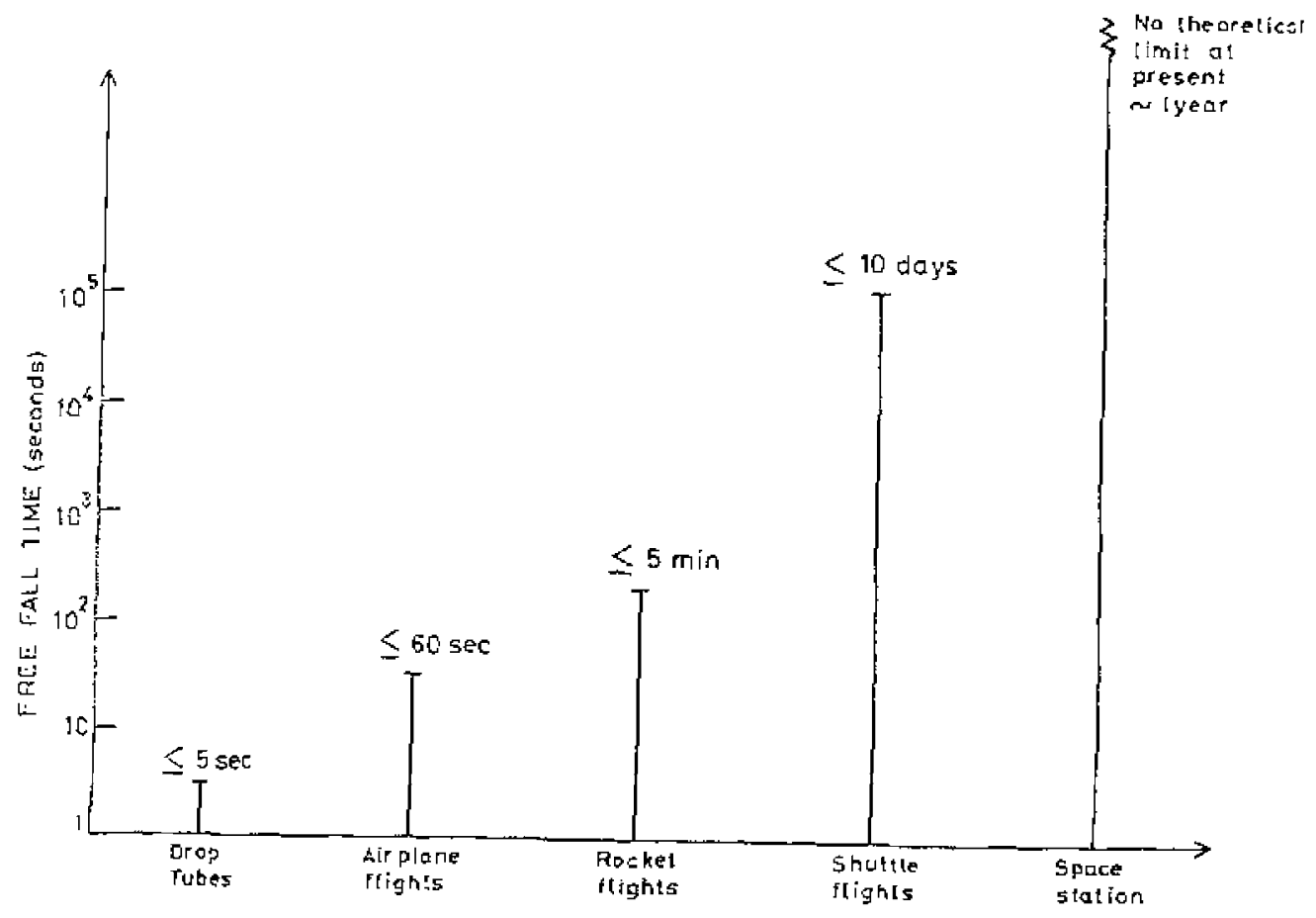

Figure 1. Microgratity processing time available during yarious techniques utilised for
microgravity research.

\section{Drop towers and drop tubes}

The two devices widely used for small-time microgravity experiments are drop towers and drop tubes. Historically, the concept finds its origin in the work of Prince Rupert in 1650 when he built the initial version of "shot towers" to produce lead shot (Johnson et al 1976). In a drop tower which normally is taller than a drop tube, the in a drag shield and dit is less stringent. The entire experimental module is encased specially designed legs and Deceleration is achieved at the bottom with the help of reduced by providing either rock absorbing thaterials. The aerodynamic drag is often the drop tower is extensively used for col thrust or by evacuating the tower. Although for materials processing. The experiment of dispersion in $\mathrm{Ga}-\mathrm{B}$ im im iscible system is one ond $\mathrm{Otto}(1975)$ to produce uniform As opposed to the drop tower drop is one of the few reported examples.

materials processing (see for example Bayuzick primarily and extensively used for is Bayuzick et al 1984). As the name indicates, it provisions are made for introd is evacuated, excepting in some special cases. Often processing units for example a inert gases at reduced pressures. The materials experiments) are positioned at thelting furnace and atomizers for solidification bottom. Both these are separted top, while a collector system is provided at the vacuum for sample insertion and baffle valves to avoid the peed for breaking the 


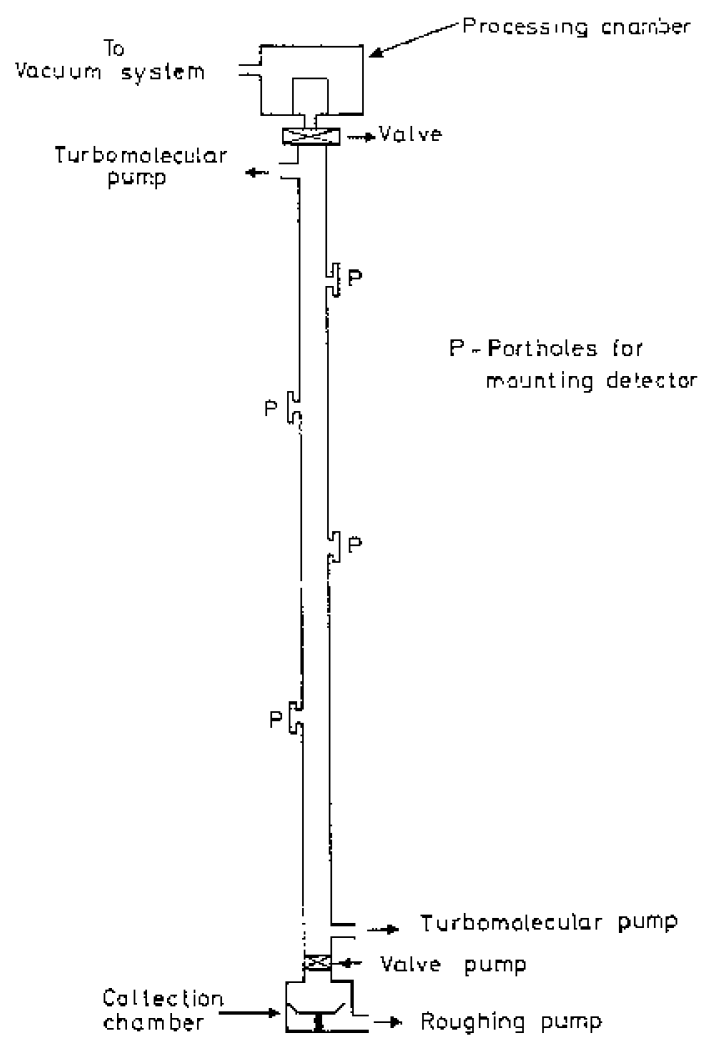

Figure 2. Diagram of a typical drop-tube showing different sections.

drop tube. Along the length of the drop tube, a series of viewing ports are normally provided, where sensors can be located to measure the physical parameters of free-failing drops. In addition there exist specialized drop tubes like cryogenic drop tube, and force-free drop tube at the Jet Propulsion Laboratory of NASA. While the former is primarily used for producing spherical microshell, the latter, which contains an arrangement of airflow through the top of the tube to match the velocity of falling drops, offers very low drag force on the sample. The time duration for microgravity condition of the falling drops ranges from $4.6 \mathrm{~s}$ for a $100 \mathrm{~m}$ drop tube to less than $1.1 \mathrm{~s}$ for drop tubes shorter than $6 \mathrm{~m}$. Probably the smallest experimental drop tubes in existence are the $2.5 \mathrm{~m}$ drop tube at Aachen, Germany and $3 \mathrm{~m}$ drop tube at the University of Wisconsin. Figure 3 gives a plot of available free-fall time as a function of the height of the drop tube assuming zero initial velocity. In case the drops are released with a velocity $t$, the fall time will be given by

$$
t_{\text {iree fall }}=1 / g\left[\left(v_{0}^{2}+2 \cdot g \cdot H\right)^{1 / 2}-v_{0}\right]
$$

where $v_{0}$ is the initial velocity, $g$ the earth's gravitational acceleration and $H$ the free-fall distance. Table 1 gives a list of drop towers and drop tubes facilities around the world.

Bașically two types of experiments can be performed in a drop tube. In one case multiple drops are allowed to fall through the drop tube and collected at the bottom for further examination. In this type of experiment, changes in parameters of the 


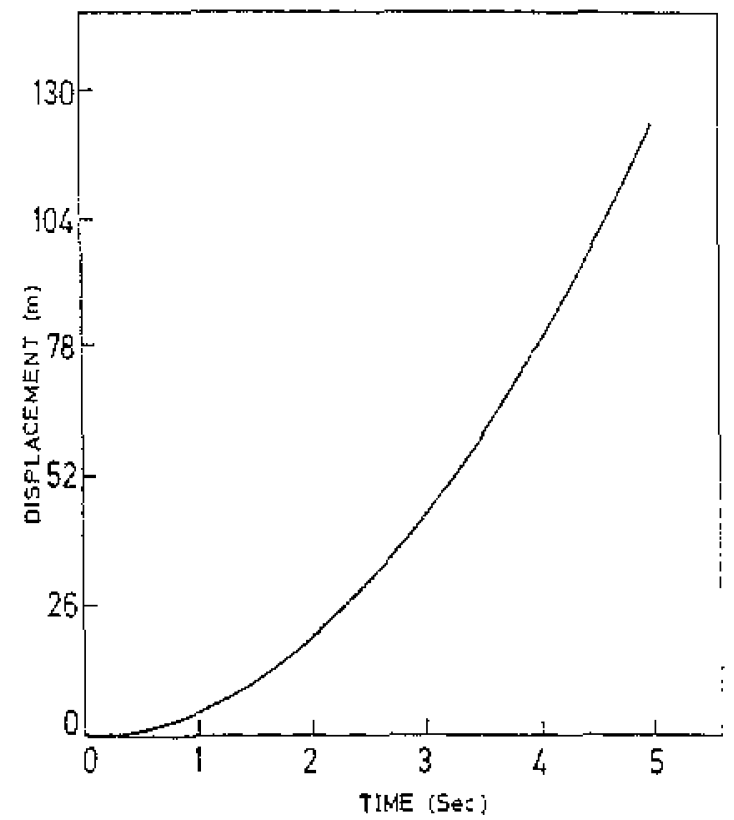

Figure 3. Available free-fall time as a function of the height of drop-tabe assuming zero initial velocity.

individual drops during free-fall cannor be measured. However, one gets a large number of samples for further examination which allows inference of processes operating during mictogravity conditions. Single drop experiments, on the other hand, offer possibilities of following changes in physical properties like temperature during free-tall of the drop through a series of well-placed sensors. Although more difficult, a successful experiment in this case offers the potential of a more determiniscic analysis of the processes which have occurred during the free fall. The sensitivity of the sensors, however, provides a critical limiting size for the drops below which detection will not be possible.

\section{Influence of microgravity on solidification processing}

Microgravity influences solidification processing both directly and indirectly. We first consider the direct effect of microgravity. Gravity essentially is an external field, which operates in the terrestial condition and is absent or negligible in magnitude under microgravity conditions. The possibility of any transformation including solidification is determined by thermodynamic conditions. However the actual transformation depends on the kinetics of the solute transport process. These include processes controlled by flactuations like diffusion, gravity and surface tension-induced mass flow and other external forces that may be operating on the phases participating in the transformation.

Let us first consider the effect of microgravity on the thermodynamic functions and in particular on the free energy. The stability of any system is determined by the minimization of the free energies. Let us consider a general phase equilibrium among 
Table 1. A list of drop towers and drop tubes available for microgravity materials science expeniments.

\begin{tabular}{|c|c|c|c|}
\hline Height (m) & \multicolumn{2}{|l|}{ Location } & Comments \\
\hline \multicolumn{4}{|l|}{ Drop towers } \\
\hline 6 & \multicolumn{2}{|c|}{$\begin{array}{l}\text { Centre of Appijed Space Technoingy } \\
\text { and Microgravity (ZARM), Bremen, } \\
\text { West Gemany }\end{array}$} & Vacuun $0.1 \mathrm{~Pa}$ \\
\hline 13 & \multicolumn{2}{|l|}{ ONERA, Palaiseau, France } & Vacuun chamber, vacuuta $10 \mathrm{~Pa}$ \\
\hline 18 & \multicolumn{2}{|l|}{ ONERA, Palaiseau, France } & $\begin{array}{l}\text { Drop in open envitonment with the aid } \\
\text { of drag shield }\end{array}$ \\
\hline 21 & \multicolumn{2}{|l|}{$\begin{array}{l}\text { Institute Nacional de Technica } \\
\text { Aerospacial, Madrid, Spain }\end{array}$} & $\begin{array}{l}\text { Drop in open environment with the aid } \\
\text { of drag shield }\end{array}$ \\
\hline 30 & \multicolumn{2}{|c|}{ Lewis Research Centre, Cleveland, USA } & $\begin{array}{l}\text { Drop in open environment with the aid } \\
\text { of drag shield }\end{array}$ \\
\hline 40 & \multicolumn{2}{|l|}{ ONERA, Chatillon, France } & Vac. $10^{-3} \mathrm{~Pa}$ \\
\hline 10 & \multicolumn{2}{|c|}{ National Aeronautical Lab, Tokyo, Japan } & $\left(10^{-2}\right.$ to $\left.10^{-3} \mathrm{~g}\right)$ \\
\hline 10 & \multicolumn{2}{|c|}{ University of Nagoya, Nagoya, Japan } & $\left(10^{-2}\right.$ to $\left.10^{-1} \mathrm{~g}\right)$ \\
\hline 100 & \multicolumn{2}{|c|}{ Marshal Space Flight Centre, USA } & $4 \times 10^{-2} \mathrm{~g}$ (Auxiliary thrust) \\
\hline 100 & \multicolumn{2}{|c|}{ Marshal Space Flight Cenlre, USA } & $4 \times 10^{-2} \mathrm{~g}$ (Auxiliary thrust) \\
\hline 100 & \multicolumn{2}{|l|}{ Dokj-Shi, Gish, Iapan } & $\begin{array}{l}\text { Evacuated }\left(10^{-4} \mathrm{~g}\right) \text {. To be operational } \\
\text { in } 1991\end{array}$ \\
\hline 110 & \multicolumn{2}{|l|}{ ZARM, Bremen, W, Germany } & $\begin{array}{l}\text { Vacuum } 1 \mathrm{~Pa}\left(10^{-6} \mathrm{~g}\right) \text {. Power can be } \\
\text { provided to be experimental module } \\
\text { during free fall }\end{array}$ \\
\hline 145 & \multicolumn{2}{|c|}{ Lewis Research Centre, Cleveland, USA } & Evacuated $\left(10^{-6} \mathrm{~g}\right)$ \\
\hline 500 & \multicolumn{2}{|c|}{ Kamsunagawer-Shi, Hokaido } & $\begin{array}{l}\text { Inside a close mine shaft }\left(10^{-4} \mathrm{~g}\right) 10 \mathrm{~s} \\
\text { free fall. To be operational in } 1991\end{array}$ \\
\hline $\begin{array}{l}\text { Drop rubes } \\
25\end{array}$ & & & Multi drop \\
\hline $2 \cdot 5$ & $\begin{array}{l}\text { Aachen, Gemiany } \\
\text { Cologne, Germany }\end{array}$ & & Multi drop \\
\hline 3 & \multicolumn{2}{|l|}{ Universily of Wisconsin } & \\
\hline $5 \cdot 5$ & $\begin{array}{l}\text { Lewis Research Centse, } \\
\text { Cleveland, USA }\end{array}$ & 1 & $\begin{array}{l}\text { Fully instrumented electro- } \\
\text { magnetic levitation is molinted } \\
\text { at the top }\end{array}$ \\
\hline $6-5$ & Cambridge, UK & 1.2 & Multiple drop atomiser \\
\hline $13 \cdot 1$ & $\begin{array}{l}\text { Jet Propulsion Laboratory, } \\
\text { California, UK }\end{array}$ & $1 \cdot 6$ & Force free drop tube \\
\hline $13 \cdot 2$ & $-40-$ & $1 \cdot 7$ & Cryogenic \\
\hline 30 & $\begin{array}{l}\text { Marshal Space Flight Centre, } \\
\text { Alabane, USA }\end{array}$ & $2 \cdot 6$ & Currently not operational \\
\hline 47 & Grenoble, France & $3 \cdot 1$ & Instrumented single drop \\
\hline 100 & $\begin{array}{l}\text { Marshal Space Flight Centre, } \\
\text { Alabama, UUSA }\end{array}$ & $4 \cdot 6$ & \\
\hline
\end{tabular}


solid, liquid and gas. The free energy of the system will consist of three terms.

$$
F=\left(F_{\mathrm{s}}+F_{1}+F_{\mathrm{g}}\right) \text { vol }+\left(F_{\mathrm{s}}+F_{1}+F_{\mathrm{g}}\right) \mathrm{gr}+\left(F_{\mathrm{s}}+F_{1}+F_{\mathrm{g}}\right) \sigma
$$

Here the subscripts $5, \mathrm{I}, g$ represent solid, liquid and gas respectively, while vol., gr. and $\sigma$ represent volume, gravity and surface tension. The volume-free energy remains unaltered under both terrestial and microgravity conditions. Ignoring this, clearly the gravity term will exert major influence in determining the stability of a system and will promote layering and sedimentation. On the other hand surface energy will play an important tole under microgravity conditions.

Miller and Ruff (1975) analyzed the effect of gravity on the free energy change during solidification. The fractional change in volume of a liquid due to a change in pressure $\Delta p$ is given by

$$
\Delta v i v=-\beta \cdot \Delta p,
$$

where $\beta$ is the isothermal compressibility. Under microgravity condition, a change in hydrostatic pressure within the liquid will be given by the standard equation

$$
\Delta p=-\rho g \cdot z \text {. }
$$

Here $\rho$ is the liquid density, $g$ the acceleration due to residual gravity in microgravity environment and $z$ the distance of the reference pressure point below the free surface of the liquid on earth.

Combining (3) and (4) we obtain

$$
\Delta v / v=\beta \cdot \rho \cdot g \cdot Z
$$

Using Turnbull's approximation of no change in specific heat between solid and liquid we can write the free energy change during solidification at an undercooled level of $\Delta T$ as

$$
\Delta G=\Delta S_{f} \cdot \Delta T
$$

$\Delta S_{f}$ is the entropy of solidification obtained by dividing enthalpy change during solidification by the thermodynamic freezing temperature. Under the microgravity
condition we have to add the external effect.

$$
\Delta G^{\prime}=\Delta G+\Delta v \Delta p
$$
where $A G^{\prime}$ represents the free energy change under microgravity condition. Using (4)
and (S)

$$
\Delta G^{\prime}=\Delta G-\beta v(\Delta p)^{2} .
$$

The actual calculations indicate that the change is extremrely small. Thus, for all practical purposes, microgravity does not have any direct effect on the thermodynamic criterion of solidification. Miller and Ruff (1975) using the free-volume model due to Cohen and Turnbuli (1959) arrived at a similar conclusion for atomic diffusivity. The direct effect of microgravity is therefore confined to (a) the absence of gravity induced convection and (b) the absence of sedimentation.

One expects significant change in mass transpott behaviour in the absence of gravity-dtiven fluid flow. There exist at least two experiments, which indicate a total absence of gravity driven convection in the liquid (Ukanawa 1974; Reed et al 1977). 
On the other hand reduced but definite microsegregation in some of the space-processed alloys (Yue and Voimer 1975) points to the presence of convective flow. It is now clear that in the absence of gravity-driven flow, the Marangoni and Sorrets effects as well as the temperature-induced microdensity fuctuation can produce convective current and induce mixing in the liquid state.

Fredriksson (1976) analysed the effect of gravity-driven convection on dendritic growth. As is weil known, convection only alters the thickness of the boundary layer ahead of the growing planar interface (Burton et al 1953). For a dendritic tip, which approximates the shape of a paraboioid, the influence on the concentration profile is negligible. On the other hand convection plays a significant role in controiling the temperature profile, since the effective heat transfer is reduced in the absence of this flow. Lack of convective flow is also expected to reduce the dendrite fragmentation and should lead to a more perfect columnar morphology. In fact the results of space experiments on ammonium chloride model system have validated such expectations (Johnston and Giner 1976).

A more profound influence of gravity on solidification processing is sedimentation. This often alters the stoichiometry, particularly, if the multicomponent melt contains elements of widely differing densities. The effect of microgravity in such a situation can be anaiysed with the help of a dimensionless parameter $H$ given by

$$
\begin{aligned}
H & =\text { sedimentation distance/diffusion distance } \\
& =d^{2} \Delta \rho g / 6 \pi v \cdot\left[t_{s} / D\right]^{1 / 2}
\end{aligned}
$$

where $d$ represents the average diameter of the separating phases, $\Delta \rho$ the density difference, $v$ the melt viscosity, $D$ the liquid diffusivity and $t_{s}$ the soaking time. Clearly as $H \ll 1$ the effect of gravity is negligible since diffusional mixing will eliminate the effect of gravity-induced segregation. For $H \gg 1$, gravity will strongly favour sedimentation. It is the latter situation which can benefit from microgravity processing. Ang and Lacy's (1979) work on AlSb is probably the best example. Although AlSb stoichiometric compound is an attractive material for solar energy conversion, it is not possible to produce stoichiometric segregation-free AlSb crystal due to the unfavourable value of $H$. The microgravity processing with a $g$ level of four orders of magnitude less will make $H \ll 1$ and could improve the situation significantly. The actual experiment in ASTP mission showed a five-foid increase in the homogeneity of AlSb specimens over that of ground-based samples:

The solidification processing of alloys containing liquid miscibility gap and monotectic reaction can be significantly influenced by gravity. The effect is pronounced if the density difference between the two liquids is large. In the zinc-lead blast furnace, rapid sedimentation is used for separating molten zinc from molten lead at the hearth of the furnace. On the other hand, many alloy development programmes require uniform dispersion of the two phases. The self-fubricating bearings and electrical contact materials are popular examples. Sedimentation often adversely affects the final microstructure. Microgravity processing is expected to overcome this difficulty.

Although the gravity-driven sedimentation is absent in the microgravity condition, convective flow and subsequent phase separation can still occur due to Marangoni flow. The driving force for such a flow is the gradient of temperature or composition which causes a gradient in interfacial tension. Migration will take place from lower surface tension to higher surface tension and hence towards lower temperature. The 
terminal velocity $V_{t}$ in such a case is given by

$$
V_{i}=2 / 15(-\nabla \sigma R / \eta)
$$

where $R$ is the diameter and $\eta$ the kinematic viscosity. The surface tension gradient $\nabla \sigma$ is given by

$$
\nabla \sigma=\frac{\partial \sigma}{\partial T} \nabla T+\frac{\partial \sigma}{\partial c} \nabla c
$$

Fredriksson (1984) studied the competition of Marangoni flow and Stokes low in $\mathrm{Zn}-\mathrm{Bi}$ immiscible alloys. With a $0.01^{\circ} \mathrm{C} / \mathrm{cm}$ Marangoni gradient and $10^{-4} \mathrm{~g}$ both flows are comparable. However, at higher temperature gradients, the Marangoni flow can be significant and reach values simfilar to that of sedimentation under terrestial condition. The segregation of $\mathrm{Bi}$ in the centre of the specimen during space experiments confirms this conclusion since radiative heat transfer always takes place from the surface. The fine dispersion can only be expected under isothermal conditions.

One of the mote exotic but possibly important applications on space processing concerns the dispersion of superconducting phase in a metallic matrix. If the fine distribution has mean interparticle spacings less than the coherence length, the matrix become superconducting by tunneling (proximity effect).

\section{Containerless solidification}

Microgravity also influences solidification processing indirectly by promoting containerless solidification. Solidification is a first-order liquid-to-solid transformation. It is a two-step process involving nucleation and growth. The steady-state nucleation rate $J$ of a solid from hiquid is given by (Christian 1975)

$$
J=n \cdot k T / h \cdot \exp \left(-\Delta G_{b} / k T\right) \cdot \exp \left(\Delta G^{*} / k T\right),
$$

where $n$ is the number of possible sites where nucleation can occur, $k$ the Boltzman's constant, $\Delta G_{b}$ the activation energy for diffusional jump, $\Delta G^{*}$ the critical free energy change for nucleation and $T$ the temperature. In the absence of any catalytic nucleation surface, $\Delta G^{*}$ is given by

$$
\Delta G^{*}=16 \pi \Gamma^{3} / 3\left(\Delta G_{v}\right)^{2}
$$

where $\Gamma$ is the liquid-solid surface free energy and $\Delta G_{v}$ the volume-free energy change associated with liquid to solid transformation. The expression indicates that for a given nucleation rate which will make the transformation detectable, a minimum amount of undercooling below the equilibrium freezing temperature is necessary. In the presence of a catalytic surface, the expression is modified by a factor $f(\theta)$ given by

$$
f(\theta)=2-3 \cos \theta+\cos ^{3} \theta
$$

where $\theta$ is the contact angle between solid-catalytic surface. The surface of the container in general provides the most common catalytic surface for solidification. $f(\theta)$ in this case is normally much less than unity. The exponential nature of the expression for nucleation rate ensures a dramatic increase in nucleation rate and decrease in undercooling necessary for detectable solidification. Thus containerless solidification which avoids catalytic nucleation sites promotes high undercooling. 
For glass-forming systems the steady-state nucleation rate given by (12) overestimates the nucleation rate and it is necessary to use non-steady-state nucleation model (Kelton and Greer 1986). Another important source of difficulty in estimating nucleation rate by the use of (12) is the lack of knowledge of specific heat of undercooled liquid. This prevents estimation of free energy change at the undercooled temperature where the nucleation is taking place. The original assumption of $\Delta C_{p}=0\left(C_{p}\right.$ is the specific heat) by Turnbull, although provided useful insight, is not valid for highly undercooled alloy melt. Recently Ramachandrarao et al (1989) developed expressions which predict free energy change of the undercooled melt more realistically. In case we introduce the foreign catalytic particles intentionally, the microgravity will promote their uniform distribution and enhance the heterogeneous nucleation. The effect of gravity on factors affecting the nucleation has been summarized by Malmejac (1978) and is presented in table 2 .

Since growth rate of a solid is in general proportional to the melt undercooling $\Delta T$ below the freezing point, the situation encountered during drop tube processing also yields a very high growth rate. This offers a variety of possibilities including new metastable phases and novel microstructures with unusual properties. The growth of solid in highly undercooled liquid corresponding to the drop tube condition has recently been analysed by Lipton et al (1987). Due to the presence of a thermal field around the growing solid, the situation is more complex. At low $\Delta T$, the growth rate follows a relationship $V=\Delta T^{n}$ with $n$ taking values between $2 \cdot 5$ and 3 . However, as the velocity increases, the limit for surface tension-controlled absolute stability is

Table 2. Effect of gravity on factors affecting nucleation (after Malmejac 1978).

\begin{tabular}{|c|c|c|c|}
\hline Factors & Direction to & Importance & Zero-g influence \\
\hline \multicolumn{4}{|l|}{$\begin{array}{l}\text { Thermodynamic driving } \\
\text { forces }\end{array}$} \\
\hline Embryo size & Maximum size $c a, 200$ atoms & High & None \\
\hline Embryo shape & Flatter with $r$ increased & High & None \\
\hline Bulk free energy & $G_{u}$ more negative $\left(T_{*} \dot{H}_{f}\right)$ & High & None \\
\hline Suface free energy & $G_{s}$ less positive & High & None \\
\hline Undercooling $(T)$ & Greater $T_{t}$ lower cooling rate & High & None \\
\hline Volume of material & Greater volume & High & None \\
\hline Foreign particles & $\begin{array}{l}\text { More particles, increased } \\
\text { wettability }\end{array}$ & High & High increase \\
\hline Foreign substrates & Inc reased wettability & High & High increase \\
\hline Liquid motion & $\begin{array}{l}\text { Increase motion (electric and } \\
\text { magnetic frelds) }\end{array}$ & High & High increase \\
\hline \multicolumn{4}{|l|}{ Composition } \\
\hline Supersaturation & Greater supetsaturation & Mediun & High decrease \\
\hline Gas content & $\begin{array}{l}\text { Increase vapour pressure over } \\
\text { the system }\end{array}$ & Medium & High increase \\
\hline Soluble intpurities & $\begin{array}{l}\text { Increase concentration difference } \\
\text { of solubilities between } S \text { and } L\end{array}$ & Medjum & $\begin{array}{l}\text { High decrease } \\
\text { none }\end{array}$ \\
\hline Radiation & Increase intensity radiation & Unknown & Probable increase \\
\hline
\end{tabular}


approached and the exponent increases very sharply. This also leads to the partition coefficient approaching unity. Thus the mecharism of growth changes from suluta? to thermal control. Since the thermal diffusion distance is larger, the latter is associated with a coarser microstructure. Similar situation also prevails in eutectic growth (Trivedi et al 1987a,b). As a consequence, one concludes that the microstructure gets finer with increasing undercooling up to a limit beyond which the scale again becomes coarser.

\section{Solidification experiments using drop tube}

For a given nucleation rate $J$ given by (12) the visible nucleation occur when $J V^{\prime} t>1$ where $V$ is the volume of the system. Thus for a given time $t$ which is determined by the flight time, nucleation depends on both the size of the liquid drop and nucleation rate. In the case of an absence of catalytic nucleation sites, $J$ can be the homogeneous nucleation rate. Thus for a given nucleation rate, decreasing the size may suppress the detectable nucleation events and the resultant phase change. Under this condition the droplet can be undercooled significantly. The amount undercooled, however, will also depend on the imposed cooling rate which is controlled by the heat transfer from the falling drop. Figure 4 shows the schematic of a time-temperature diagram where the locus of the detectable nucleation rate is plotted. The slopes of the straight lines indicate the cooling tates. It is clear that. Ior a given time, higher rate has the potential for achieving larger undercooling. The heat transfer from a falling droplet can be easily computed from the relation

$$
\mathrm{d} Q / \mathrm{d} t=-E A \sigma\left(T^{4}-T_{0}^{4}\right)-h A\left(T-T_{0}\right)
$$

where $\varepsilon$ is the emissivity of the liquid surface, $\sigma$ the \$tefan-Boltzman constant and $h$

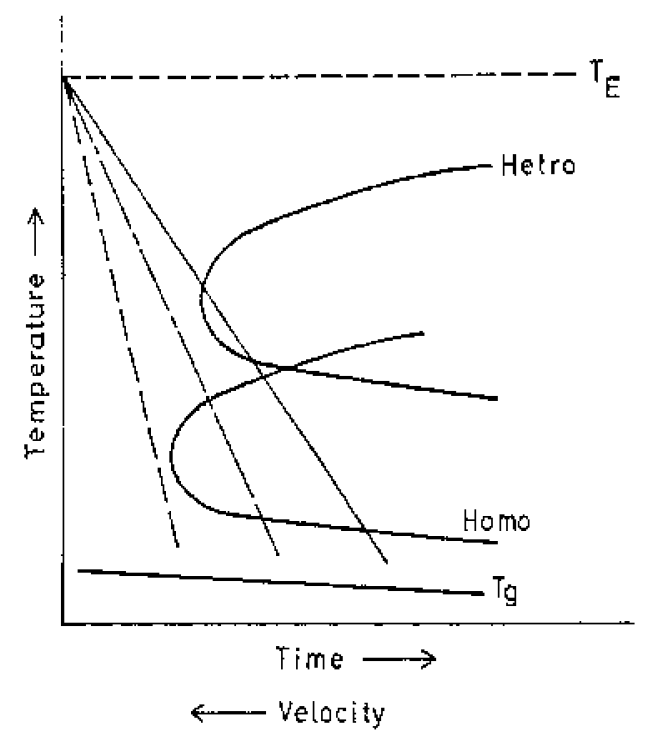

Figure 4. Time-temperature diagram plotting the locus of tetactable nucleation rates in falling drops. 
the heat transfer coefficient. $A, T_{0}$ and $T$ are surface area, ambient and droplet temperatures respectively. In case of a perfect vacuum, the heat transfer is only controlied by the radiation and the first term on the right side is sufficient.

In the presence of a gas, an additional mode of heat transfer needs to be considered. Although it is generaily dificult to experimentally determine beat transfer coefficient $h_{,}$it can be estimated for an isolated sphere in flowing gas having $17<N_{\mathrm{Re}}<1700$ ( $N_{\text {Re }}$ is the Reynoid's number) by using the following equation

$$
h=0.37 K_{f} / D\left(D_{v}, V / v_{f}\right)^{0 \cdot 6} \text {. }
$$

Fere $K_{f}$ is the thermal conductivity, $v_{f}$ the kinematic viscosity and $V$ the relative velocity of the gas. The expression clearly establishes a significant improvement of heat transfer, if some inert gas is leaked into the drop tube. Figure 5 gives typical cooling curves for different sizes of aluminium droplets falling in helium gas atmosphere. It is obvious that smaller droplets will cool faster. Thus in case the nucleation event is avoided, smaller droplets will undercool more. An analysis of the Einal droplet temperature as a function of drop size for a drop time of $1.2 \mathrm{~s}$ in different atmospheres was carried out by Cochrane et al (1988) for molten aluminium. It is clear that the undercooling achieved is insignificant in vacuum, while it can be considerable in the presence of inert gases. Further, the effect of conductivity of different gases has a strong influence only in a narrow size range of droplets. Equation (15) also indicates that high melting point alloys will have a higher cooling rate and therefore will undergo greater undercooling in the drop tube. Figure 6 shows a typical plot of flight time available in a drop tube and the supercooling for molten niobium for five different sizes of droplets (Lacy et al 1981). It is obvious that beyond a minimum free time a small increase in free-fall time increases the achievable undercooling significantly. However, even a smali improvement in free-fall time requires a large increase in drop tube height (figure 3). Thus the alternative of introducing a gas to increase the cooling rate for achieving higher undercooling is more attractive. Of course the gas will generate a drag force which will reduce the microgravity condition. With the knowledge of velocity of the droplet at the end of

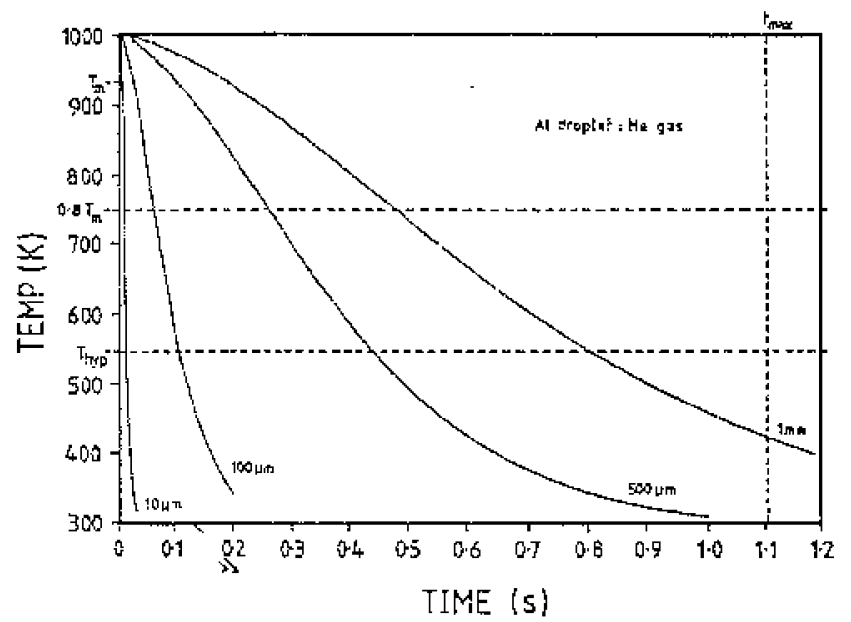

Figure 5. Droplet cooling curves for aluminium dropiets falling in $\mathrm{He}$ at atmospheric pressure (after Cochran et al 1988). 


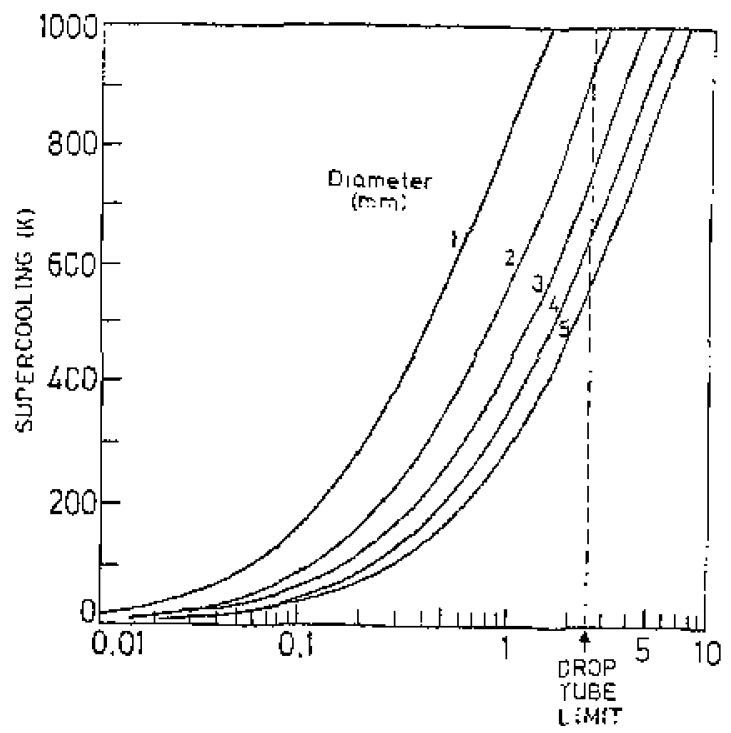

Figure 6. A typical plot of flight times available in a drop tube and the supercooling for molten Niobium Cor five different sizes of droplets (after Bayuzick et al 1984).

the free fall $(V)$, Reynold's number $\left(R_{e}\right)$ and the gas properties, the drag coefficient can be obtained from the expression (Bayuzick et al 1984)

$$
C_{b}=24 / R_{e}+6\left(1+R_{e}^{1 / 2}\right)+0 \cdot 4,
$$

where $C_{D}$ is the drag coefficient. The drag force is given by

$$
F_{D}=C_{D} \cdot A \cdot \rho V^{2} / 4
$$

where $A$ is the area normal to the free stream and $\rho$ the density of the gas at the thin film temperature. Figure 7 shows the drag force that develops on a $\mathrm{Nb}-27 \% \mathrm{Ge}$ alloy at $100 \mathrm{~m}$ level as a function of He gas pressure. It is clear that for the larger droplets the drag is much less, while for maller droplets it can be significant. Recently a detailed computer modelling of heat transfer of a falling droplet incorporating different atmospheres, their effect on boundary layer and the evolution of heat during solidification has been developed by Hallmann (1989) using finite element technique.

It is preferable to express undercooling of a liquid in terms of a dimensionless normalized undercooling defined as $T_{\text {undercooling }} / T_{\text {bypercostrg. }}$. The hypercooled state is defined as a state of liquid when the entire latent heat of solidification is removed without effecting a phase change. This is given by the expression

$$
L=C_{p} \cdot \Delta T \text {, }
$$

where $\Delta T$ is $T_{f}-T$. Here $L$ is the latent heat of freezing, $C_{p}$ is the specific heat and $T_{f}, T$ are freezing and undercooled temperature. The hypercooled state, therefore, represents a state of liquid, where the solidification, if nucleated, will proceed adiabatically. Extensive investigations on undercoolability of pure metals were carried out using the $100 \mathrm{~m}$ drop tube of NASA, USA and more recently the Grenoble drop tube. Figure 8 shows the results. Under vacuum, the hypercooled state can be achieved only for high melting point metals. However, the introduction of a small amount of 


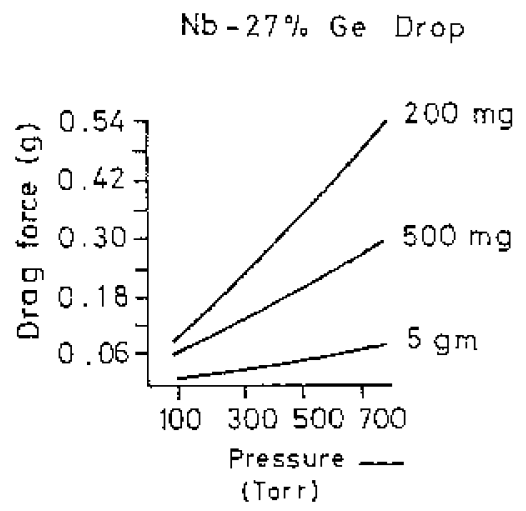

Figure 7. A plot of drag force that will develop in Nb-Ge alloy under different helium gas pressure at $100 \mathrm{~m}$ level.

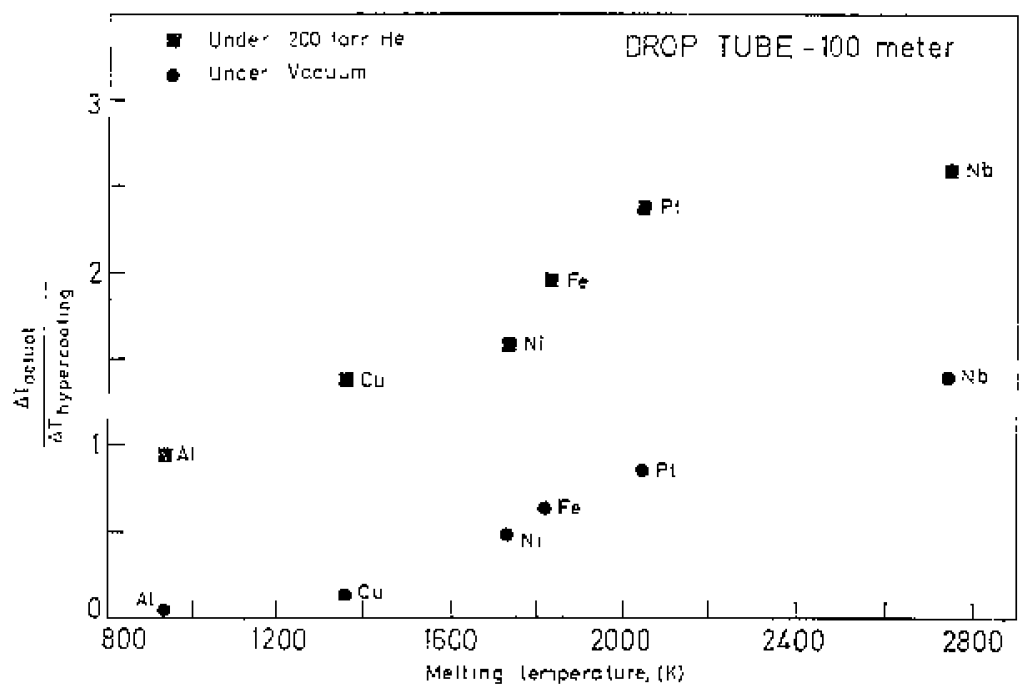

Figure 8. Undercoolability of pute thetals as achieved in $100 \mathrm{~m}$ drop tube of NASA, USA under yacuum and with 200 torr $\mathrm{He}$ filling (ater Bayuziek et ai 1984).

He is sufficient to achieve hypercooling of large number of metals. A summary of undercooling achieved for high melting point metals in the 100 and $48 \mathrm{~m}$ drop tubes is given in table 3. It can be seen that the normally used dimensionless undercooling $\left(\Delta T / T_{f}\right)$ of a value as high as 0.28 is achieved for the case of rhenium (Vinet $e t$ al 1991). The value $0-2$ was often believed to be the limit of undercoolability in early nucleation literature (Tumbull 1950). The current excitements on drop tube results have recently been discussed by Cahn (1991).

The morphological stability and the development of grain size of germanium at high undercooling have been recently studied using a drop tube (Evans et al 1989). This work establishes a transition from edgewise growth (faceted growth) to normal growth (nonfaceted growth) at a critical undercooling of $1057 \mathrm{~K}$. Evidences were also 
rable 3. Lindercooling achieved in the 100 and 48 drop tube in few selected telractory metals.

\begin{tabular}{|c|c|c|c|}
\hline Stetals & $\begin{array}{l}\text { Melting } \\
\text { point (K) }\end{array}$ & $\mathrm{T}$ & $T_{i}^{\prime} T_{m}$ \\
\hline Tungiten:" & 3450 & 975 & 0.14 \\
\hline Rhenium ${ }^{*}$ & 3690 & 530 & 028 \\
\hline Niobilum & 2741 & 525 & 0.19 \\
\hline Iridiun & 2727 & 430 & $0-16$ \\
\hline Hafnium & 2500 & 530 & 021 \\
\hline Rhadium & 2238 & 342 & 0.15 \\
\hline
\end{tabular}

* $48 \mathrm{~m}$ drop tube

presented for a critical dendritic velocity beyond which grain refinement effect could be observed.

\section{Drop tube processing of multicomponent alloys}

The drop tubes can be effectively used to study the microstructural evolution and metastable phase formation in binary and ternary alloys. These experiments utilize both the principle of containceless solidification to achieve high undercooling and the lack of gravity-driven flujd flow and sedinjentation to synthesize novel microstiuctures. We shall now describe a selection of these teșults.

As pointed out earlier, systems exhibiting liquid immiscibility have attracted attention of space scientists in?oived in materials processing because of the possibility of uniform dispersion of the two liquids to the liquio state and retaining this distribution during solidification. Drop tubes are used to study such microstructural evolution. Experiments with slightly hypermonotectic $A u-65$ at $\% \mathrm{Rh}$ alloy in a $100 \mathrm{~m}$ drop tube reveals a coatse but fairly uniform distribution of gold in rhodium (Andrew and Robinson 1986). Cochrane et al (1988) studied the solidification behaviour of $\mathrm{Ag}-\mathrm{Pb}$ ailoys which exhibit a subneryed miscibility gap that can be accessed during undercooiing. The drop tube-processed samples indeed exhibited the expected uniform dispersion of lead in silver (figure 9). In this respect the results of drop tube-processed samples duplicate the effects observed during rapid solidification. This aspect has been discussed by Ramachandrarao (1982).

The effect of drop tube processing on eutectic structure is mainly through the undercooling effect of the containerless processing. Shong et al (1987) studied the eutectic spacing of InSb-Sb elitectic alloy as a function or undercooling and compared it with results obtained through drop titbe processing. The lamellar spacings agree with those expected for the undercooling attained in the drop tube. These researches also reported a rod to lamellar morphological transition. Chattopadhyay et al (1990a) attempted to study the microstructural evolution of $\mathrm{Al}-\mathrm{Cu} \mathrm{Al}$ evtectic alloy using the $6 \mathrm{~m}$ drop tube at Cambridge. The drop tube processing in the presence of helium yields two types of microstructures. In one case the microstructure contains primary * Al dendrites indicating a shift in eutectic point. The eutectic remains lamellar (figure 10a). in certain drops complex eutectic morphologies could be seen (figure 10b). The undercooling calculated from the lamellar spacings turned out to be small, 


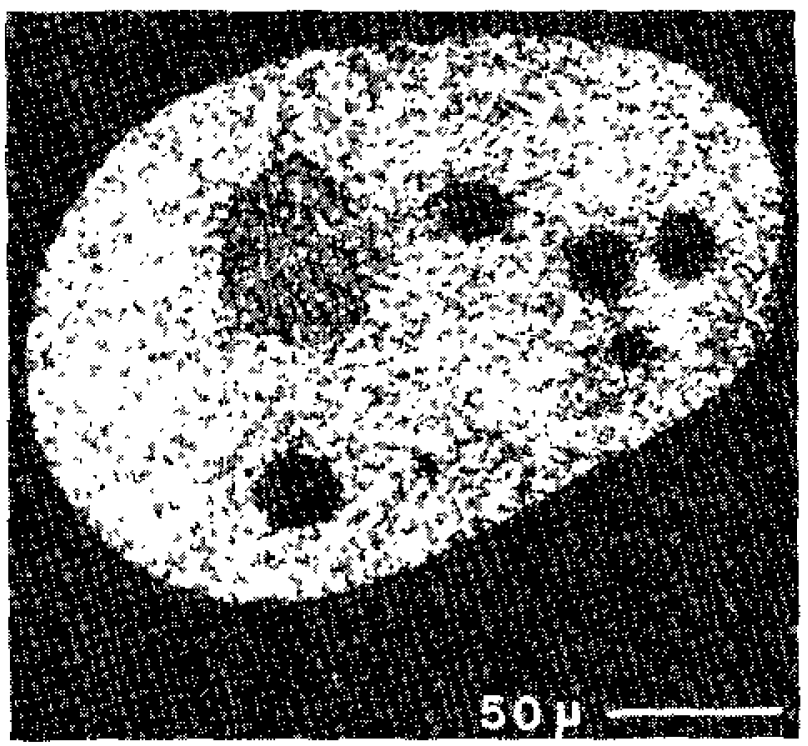

Figure 9. Uniform distribution of lead in silver sample processed in drop tube (Cochran et al 1988).

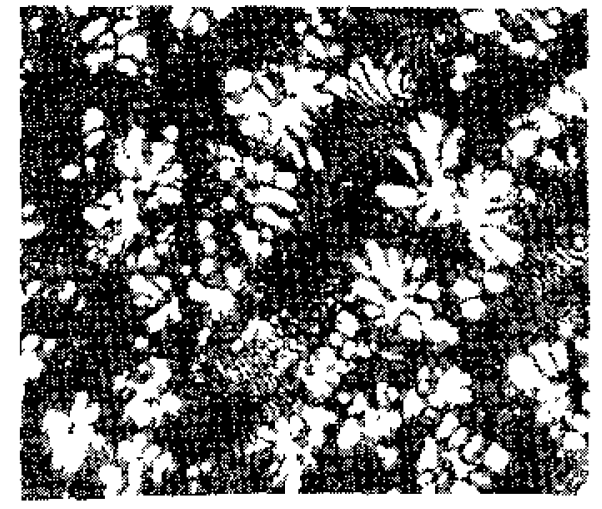

SIZE RANGE 1000 HI -600 ti

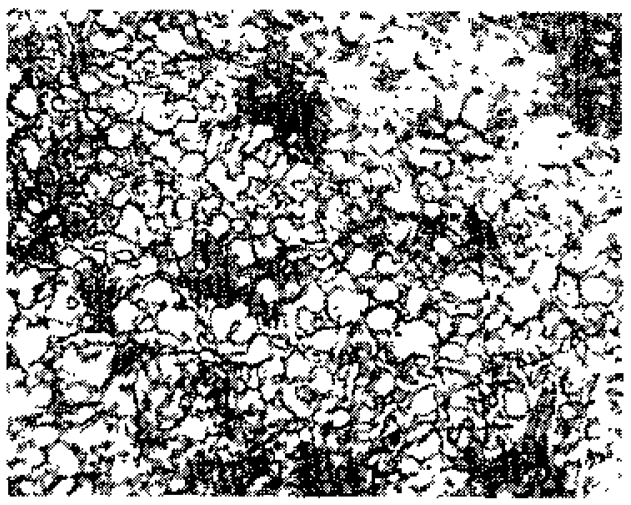

$504 \pi$

Figure 10. Microstructure of drop tube processed Al-Cu eutestic alloy, (a) Primary $\alpha$ and lamellar eutectic microstructure indicating shift in eutedic point. (b) A complex degenerate structure that could be observed in occasional drops.

indicating either less undercooling or significant coarsening of the lamellae. The presence of helium gas also induced significant convective flow which affected the microstructure (figure 11). This effect is more prominent in smaller droplets where the drag force will be larger. The occurrence of primary $\alpha$ is consistent with the-result of the space-borne experiments on $\mathrm{Ag}$. Cu alloys (Batbieri and Patuelli 1988) and is believed to be due to the increase in undercooling before solidification. 


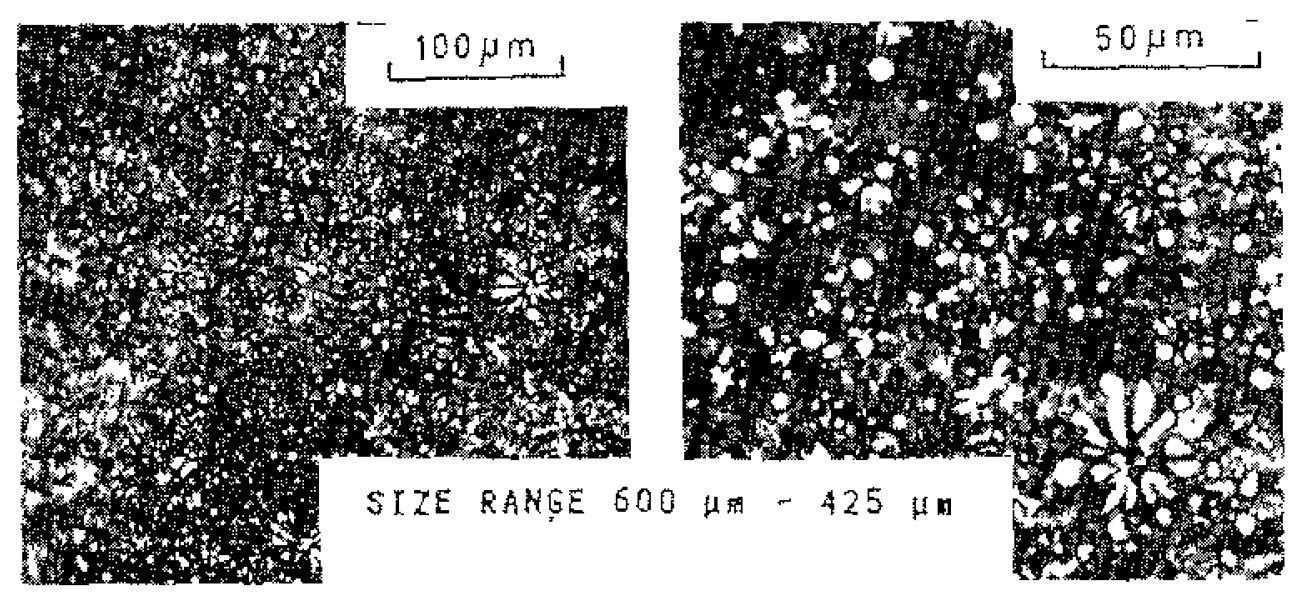

Figure 11. Drop tube processed $\mathrm{A} 1-\mathrm{Cu}$ eutectic microstructures under helium atmosphere indicating significant convective flow in the liquid.

One of the earliest published experiments on the metastable phase transformation using drop tubes is that of Lacy et al (1982) who carried out drop tube experiments on $\mathrm{Nb}-\mathrm{Ge}$ alloys. Under an equilibrium condition, niobium-rich alloys form $\beta$ phase with A15 structure. However the phase is Ge-deficient and forms a defective A15 structure resulting in very low superconducting transition temperature. The drop tubeprocessed samples produce stoichiometric $\mathrm{Nb}_{3}$ Ge phase exhibiting a significantly higher superconducting transition temperature. Microstructures of these alloys were characterized extensively by Evans et al (1986) who concluded that in drop tube-processed samples the superconducting $\beta$ phase forms directly from the melt. Recently the solidification behaviour of drop tube-processed Al-8wt\% Fe alloy was studied in detail using the $65 \mathrm{~m}$ drop tube of Cambridge University under a $\mathrm{He}$ pressure of $80 \mathrm{KPa}$ (Cochrane et al 1989). These experiments utilized containerless solidification to undercool the alloy drops under a relatively high heat transfer condition. Six distinctly different types of morphologies were observed. A statistical analysis of the occurrence of these microstructures for different droplet sizes was carried out. Simultaneously model calculations of the growth rate of various possible structures in undercool Al-8wt \% Fe alloy as a function of bulk liquid ternperature were undertaken using the recently developed growth theories (Trivedi et al 1987a,b). This enabled these researchers to plot the calculated interface velocities as a function of undercooling for different phases and growth forms. These provide windows where different microstructures will be kinetically favoured. The analysis is remarkably successful in predicting the evolution of complex microstructures and their transitions as a function of droplet size in Al- $8 \% \mathrm{Fe}$ alloy.

Similar experiments on metastable phase formation in $\mathrm{Fe}-\mathrm{Ni}$ alloys were carried out by Shong et al (1987) who measured the undercooling obtained in $2 \mathrm{~mm}$ falling drop as a function of nickel concentration and obtained the evidence of the formation of metastable bce phase in certain compositions. The undercooling values are consistent with the metastable phase diagram of $\mathrm{Fe}-\mathrm{Ni}$ alloys.

A recent drop tube experiment involves a hypereutectic Al-5.4\% Co alloy (Chattopadhyay et al 1990b). Under normal solidification conditions, one observes an eutectic mixture of $\alpha \mathrm{Al}$ and $\mathrm{Al}_{9} \mathrm{Co}_{2}$ phase together with primary $\mathrm{Al}_{9} \mathrm{Co}_{2}$ phase. 
However, drop tube samples show a hierarchy of complex microstructures (figure 12). $X$-ray diffraction did not reveal any new metastable phases. Thus drop tube processing was successful in bringing significant morphological transition in this alloy. Efforts are being made to understand them with the help of non-equilibrium extension of equilibrium phase diagram and gravity.

In many alloy systems, the high undercooling of the melt leads to glass formation. Using $100 \mathrm{~m}$ drop tube at NASA spheres of ternary $\mathrm{Pd}-\mathrm{Cu}-\mathrm{Si}$ metallic glass were produced (Steinberg et al 1981). A detailed scientific study of kinetics of crystal

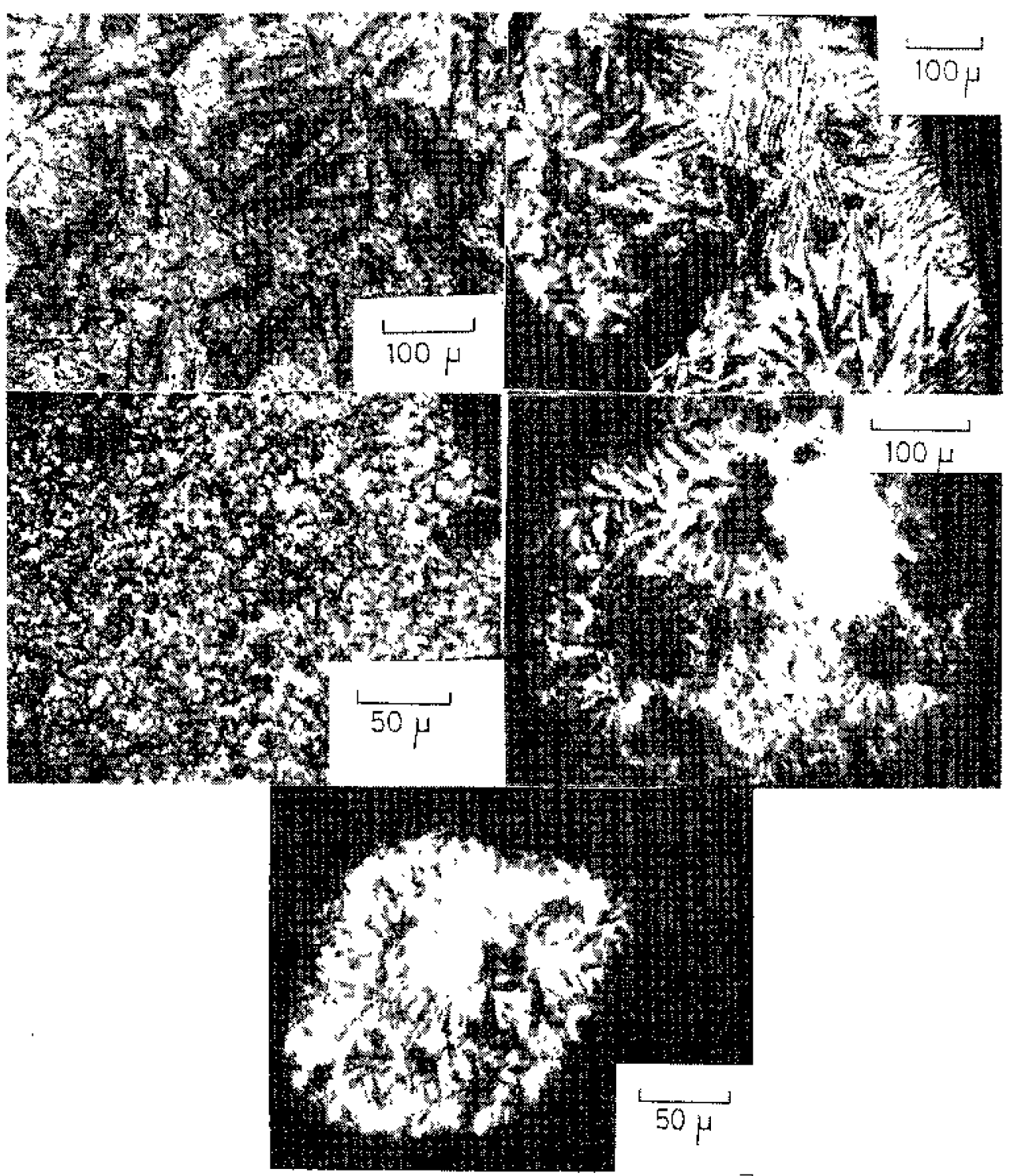

Figure 12. Hierarchy of complex microstructures in droptube processed samples of hypereutectic Al-5.4\% Co alloy. Significant morphological transitions could be observed when compared to normally solidified samples. 
nucleation in Pd-Si metallic glass was carried out by Drehman and Turnbull (1981) using a drop tube. In these multiple droplets experiments, fraction glassy as a function of drop diameter was experimentally determined for two alloys of $\mathrm{Pd}_{83} \mathrm{Si}_{17}$ and $\mathrm{Pd}_{82} \mathrm{Si}_{18}$. These data were then compared with the prediction of three nucleation models namely homogeneous nucleation, heterogeneous nucleation and heterogeneous surface nucleation. The results (figure 13) indicate heterogeneous surface nucleation to be the main obstacle to metallic glass formation.

Recently Shong et al (1987) studied the glass formation in $\mathrm{Ni}-\mathrm{Nb}$ alloys and analysed the effect of both particle sizes and gas atmosphere on the glass formation ability of $\mathrm{Ni}-52.9 \mathrm{wt} \% \mathrm{Nb}$ alloy. The results are consistent with the undercooling that can be achieved under different conditions. The effect of containerless solidification on the glass formability was studied by Kiminami and Sham (1986) as well as by Gillessen et al (1988) using $\mathrm{Pd}_{77.5} \mathrm{Cu}_{6} \mathrm{Si}_{16.5}$ alloys. Completely glassy sphere could be produced with up to $900 \mu \mathrm{m}$ diameter corresponding to a critical cooling rate of $890 \mathrm{~K} / \mathrm{s}$. Gillessen et al (1988) also established a pronounced effect of meit overheating on the glass formability. The glass forms more easily if the melting temperature is higher. Detailed studies on the glass formability in $\mathrm{Cu}-\mathrm{Zr}$ system revealed that containerless processing significantly improves the glass formability in these alloys (Gillessen and Herlach 1988). The critical cooling rate for glass formation is $\sim 4 \times 10^{4} \mathrm{~K} / \mathrm{s}$ for $\mathrm{Cu}_{56} \mathrm{Zr}_{44}$ while it is $8 \times 10^{3} \mathrm{~K} / \mathrm{s}$ for $\mathrm{Cu}_{62} \mathrm{Zr}_{38}$. These values are 3 and 20 times less than that needed for forming glass by splat-cooling techniques.

The materials presented give only a glimpse of the possibilities that a drop tube offers with respect to liquid-to-solid transformation. Other equally exciting possibilities exist. For example, recently the drop tube was used for carrying out critical point wetting experiments in liquid (Kaukler 1988). Drop tube provides fresh opportunities for understanding the particle pushing/trapping in liquid and composite growth. The possibilities in the field of polymers, organic and bio-organic fiuids as well as gels,

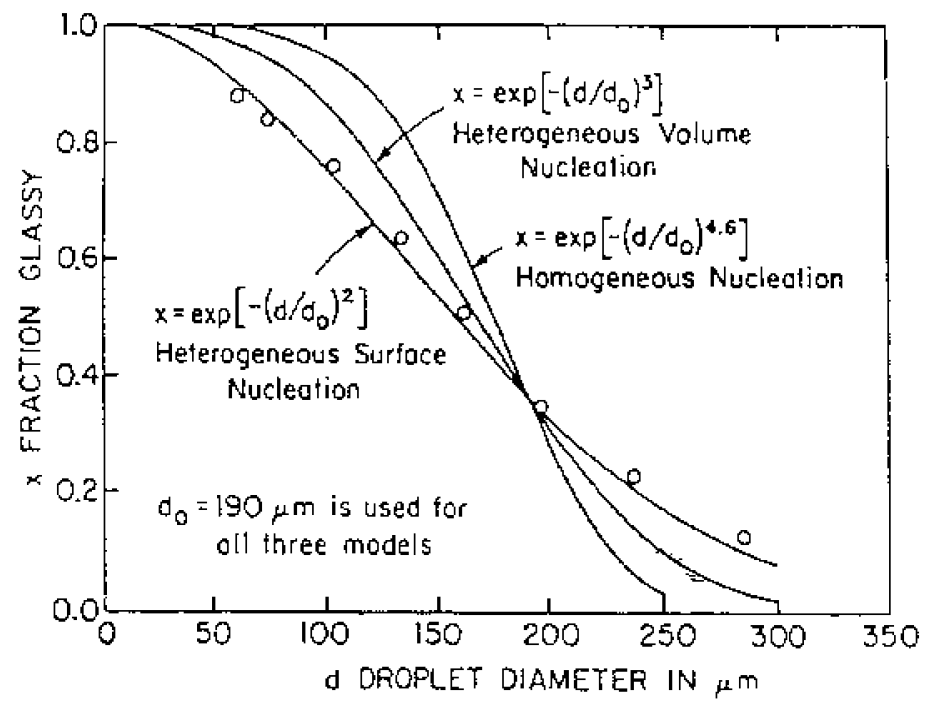

Figure 13. Comparison of observed data on fraction transformed to metallic glass as a function of drop diameter in $\mathrm{Pd}_{83} \mathrm{Si}_{17}$ samples processed in droptube and calculated on the basis of three nucleation models. 
clusters and nanocrystals are yet to be explored. It is necessary for the scientific community to get sensitized with the possibilities. Although the flight time is limited it is possible to design sound experiments to generate new scientific knowledge.

\section{Acknowledgements}

The authors thank Professors $\mathrm{S}$ Ranganathan, $\mathrm{P}$ Ramachandrarao and $\mathrm{S}$ Banerjee for many fruitul discussion. Special thanks are due to Drs B Cochran, L Greer and V T Swamy for ailowing us to use some of the unpublished work.

\section{References}

Andrew J B and Robinson M B 1986115 th Annual TechnicaI Meeting of AIME, New Orleans, Louisiana, 68 Ang C and Lacy L 1979 Metall. Trans. A10 519

Barbieri $\mathrm{F}$ and Patuelli $\mathrm{C} 1988$ in Experimental methods for microgravity materials science research R A Schiffman, AIME, p. 87

Bayuzick R J, Evans N D, Hofmeister W F, Johnson K R and Robinson M B 1984 Adu. Space Res. 485 Burton J A, Prim R C and Slichter W A 1953 J. Chem. Phys. 211987

Cahn R W 1991 Nature (London) $\mathbf{3 4 9} 736$

Chattopadhyay K, Swamy V T and Cochrane R F 1990 a unpublished work

Chattopadhyay K, Raji T, Cochrane R F and Greer A L 1990b unpublished work

Cohen M H and Tumbull D 1959 J. Chem. Phys. 31 1,64

Christian J W 1975 in The theory of transformation in metals and alloys (London: Pergamon Press)

Cochrane R F, Evans P V and Greer A L 1988 Mater. Sci. Enga. 9899

Cochrane R. F, Newcomb S B, Evans P V and Greer A. L 1989 in Rapid solidification processing and technology (eds) O N Mohanty and C S Sivaramakrishnan, Trans Tech, Switzerland, 21 (also in Key Engineering Material, $38-39$ (1989) 21)

Drehman A J and Turnbull D 1981 Ser. Metall. 151981

Evans P V, Vitta S, Hamerton R G, Greer A L and Turnbull D 1990 Acta Metall. 38232

Evans N D. Holmeister W H, Bayuzic R I and Robinson M B 1986 Marall. Trans. A17 973

Fredriksson H 1976 Proc. Second European Symposium on Materials in space, Frascati, 9-8. April, ESA-SP-114, 29

Fredriksson H 1984 Proc. of RIT/ESA/SSC-Workshop Jarva Krog, Sweden, ESA-SP-219, p. 25

Gillessen F and Heralach D M 1988 Mater. Sci. Engg. 97147

Gillessen F, Herlach D M and Feurbacher B 1988 J. Less Common Metals 145145

Hallmann W 1989 Int. J. Microgr. Res. Appl. 113

Hofmeister W H, Evans N D, Bayuzic R S and Robinson M B 1985 Rapidly quenched metals (eds) S Steebs and $\mathbf{H}$ Warlimont (Amsterdam: North Holland) p. 56

Johnston M H and Giner C S Report on SPAR experiment No. 74-21. May 1976, NASA Marshal Space Flight Centre

Johnson W, Manalis A G and Hund $\mathrm{H} 1976$ Metal. Met. Forming March 68

Kaukler W F 1988 in Experimental methods for microgravity materials science research (ed) R A Schiffman, AIME 13

Kelton K F and Greer A L 1986 J. Non Crystalline Solids 79295

Kiminami C S and Sham P R 1986 Acta Metall. 342129

Lacy L L, Robinson M B and Rathz T J 1981 J. Cryst. Growth 5144

Lacy L L. Rathz T J and Robinson M B 1982 J. Appl. Phys. 51682

Lacy $\mathrm{L} L$ and Otto $\mathrm{H} G 1975$ AJAA J. 13219

Lee M C 1983 SAMPE J. 13 7; Also in 1986, Aerosp. Am. 2472

Lipton J, Kurz W and Trivedi R 1987 Acta Metall. 35 957-965

Mal.hejac Y 1978 Proc. R. Soc. London A361 167

Miller R I and Ruft R C 1975 J. Appl. Phys. 46208

Mckannan E 1977 Aluminium 53376

Ramachandrarao P 1982 Bull. Mater. Sct. 4267 
Ramachandrarco P. Dubey K S and Lele S 1989 Acta. Metall. Mater. 372795

Reed R E, Uelhoff W and Adair H L 1987 ORNL Report 76-113

Shong D S, Graves J Ar Vjjee Y and Perepezko J H 1987 Mater. Res. Soc. Symp. Proc. 8717

Steinberg J, Lord A E. Lacy L L and Johnson J 1981 Appl. Phys. Lett. 38131

Trivedi R, Lipton J and Kurz W 1987a Acta Metall. 35965

Trivedi R, Manguin P and Kurz W $1987 \mathrm{~b}$ Acta Metall. 35971

Turnbult D 1950 J. Appl. Phys. 211022

Ukanawa A 1974 Skylab results, Third Space Processing Symposiun (ed.) MPL Seibel, 1 \& 2, (NASA)

Vinet B, Cortela I. Favier J J and Desre P 1991 .4ppl. Phys. Lett. 5897

Yue J T and Volmer F W 1975 J. Cryst. Growth 29329 